\title{
¿POR QUÉ SE IDENTIFICAN TAN POCAS VÍCTIMAS DE TRATA DE SERES HUMANOS? ${ }^{1}$
}

\author{
Autora: Carmen Meneses Falcón \\ cmeneses@comillas.edu \\ Universidad Pontificia Comillas
}

\begin{abstract}
Resumen
En este trabajo se reflexiona sobre el número de víctimas de trata de seres humanos identificado en España en los últimos años. 2.209 víctimas con fines de explotación sexual y 439 con finalidad de explotación laboral han sido identificadas entre los años 2014 y 2017. Se trata de cifras reducidas si se contrasta con las informaciones de liberación de víctimas que ofrecen los medios de comunicación social. Los datos de organismos internacionales sitúan a la trata con fines de explotación laboral superior en volumen a la sexual y se cuestiona las bajas cifras obtenidas y los posibles obstáculos que pueden estar implicados. Se profundiza sobre las dificultades de detección e identificación de las víctimas de trata de seres humanos, encontrando factores relacionados con la situación personal de
\end{abstract}

${ }^{1}$ Este artículo forma parte de la investigación: "Visibilizando a las víctimas de trata: actuando contra la trata de mujeres con fines de explotación sexual", Proyecto Nacional de I+D+I, con referencia: CSO2014-55209-P. 
las víctimas, aspectos que los profesionales y las instituciones deben mejorar para avanzar y la necesidad de clarificar realidades sociales diferentes que se conceptualizan como similares.

Palabras clave: Trata de seres humanos; víctimas; explotación sexual; prostitución.

\title{
Why so few victims of trafficking in human beings are identified?
}

\begin{abstract}
This paper reflects on the number of victims of human trafficking identified in Spain in recent years. 2,209 victims for the purpose of sexual exploitation and 439 for the purpose of labor exploitation have been identified between 2014 and 2017. These are small figures if contrasted with information on the release of victims offered by social media. The data from international organizations place trafficking for labor exploitation purposes higher in volume than sexual exploitation and question the low figures obtained and the possible obstacles that prevent adequate identification. The difficulties of detection and identification of victims of trafficking in human beings are addressed, finding factors related to the personal situation of the victims, aspects that professionals and institutions must improve in order to advance and the need to clarify different social realities, conceptualized as similar.
\end{abstract}

Key words: Trafficking in Human Beings; victim; sexual exploitation; prostitution.

Fecha de recepción: 09/02/2019

Fecha de aceptación: 18/07/2019

\section{INTRODUCCIÓN}

En el 2010 se introdujo en el Código Penal el artículo 177bis que penaba el delito de trata de seres humanos cumpliendo así los compromisos que se adquirieron cuando España firmó el Protocolo de Palermo en el 2000². Posteriormente

${ }^{2}$ Protocolo de las Naciones Unidas para Prevenir, Reprimir y Sancionar la Trata de Personas, Especialmente Mujeres y Niños (también conocido como el Protocolo contra la trata de personas). 
diferentes directivas europeas han ido matizando, ampliando y dirigiendo la lucha contra la trata de seres humanos en España (Castaños, 2014). En la modificación del Código Penal (CP) del 2015 se amplió el tipo penal introduciendo alguna de las finalidades de la trata de seres humanos en el punto uno del artículo citado, que no quedaba recogida en el Código anterior. De tal forma que España se encuentra con una normativa vigente suficiente, e incluso con una alta penalidad comparada con otros países (de León, 2010).

Desde el año 2008 se convocan subvenciones y ayudas por parte de la Delegación del Gobierno para la Violencia de Género para atender a las víctimas de trata con fines de explotación sexual, no contemplando otras modalidades de explotación. Se han creado dos Planes Integrales de Lucha contra la Trata, el del 2009-2012 y el del 2015-2018, que han contemplado distintas acciones de coordinación y formación entre los profesionales y administraciones. Los cuerpos policiales del Estado (Policía Nacional, Guardia Civil, Mossos de Esquadra y Ertzaintza) han destinado unidades para perseguir el delito de trata y proteger a las víctimas rescatadas de los tratantes. Y otras muchas acciones que se han venido desarrollando en los últimos 15 años, de las que no pretendemos aquí hacer un inventario, pero si señalar los esfuerzos en la detección, identificación y liberación de las víctimas, centrado principalmente en fines de explotación sexual. Si se comparan los casos mencionados por los medios de comunicación ${ }^{3}$ llama la atención que la identificación de las víctimas de trata sea tan reducida en los informes oficiales. Centrándonos en los dos tipos de trata de seres humanos que aglutinan más casos (Eurosat, 2014), las de finalidad sexual y laboral, y siguiendo los datos de la Fiscalía General del Estado en la sección de extranjería, el número de víctimas identificadas no llega al millar en el primer tipo y ni a dos centenas en el segundo caso, además de producirse una disminución cada año -exceptuado la sexual en el último año-, es decir, en el último año se han identificado como víctimas de trata laboral y sexual a 456 personas, siendo el $85 \%$ con finalidad sexual. En el último Plan Integral de lucha contra la trata ${ }^{4}$ se estimaba el número de mujeres que ejercían la prostitución era de 45.000 en el 2012, si se hubiese mantenido estable esta cantidad a lo largo de los últimos años, diríamos que la identificación de víctimas supone entre el 0,8\% y el 2\% de las personas que ejercen la prostitución.

\footnotetext{
${ }^{3}$ Véase noticia del la Agencia Efe (5 dic 2018). La trata para explotación sexual mueve 5 millones de euros al día en España, https://www.efe.com/efe/espana/sociedad/la-trata-para-explotacion-sexual-mueve-5-millones-de-euros-al-dia-en-espana/10004-2531981

${ }^{4}$ http://www.interior.gob.es/documents/642012/5707784/Plan+Integral+Trata+2015/f74fd06248ce-47d4-bedf-aae0ce2a0509 (p. 37).
} 
Tabla 1. Trata con fines de explotación sexual

\begin{tabular}{|c|c|c|c|c|c|}
\hline Años & Mujeres & Hombres & $\begin{array}{c}\text { Mujeres } \\
\text { menores }\end{array}$ & $\begin{array}{c}\text { Hombres } \\
\text { menores }\end{array}$ & TOTAL \\
\hline 2014 & 871 & 12 & 36 & 1 & 920 \\
\hline 2015 & 455 & 37 & 44 & & 536 \\
\hline 2016 & 337 & 1 & 28 & & 366 \\
\hline 2017 & 354 & 14 & 19 & & 387 \\
\hline
\end{tabular}

Tabla 2. Víctimas con fines de explotación laboral

\begin{tabular}{|c|c|c|c|c|c|}
\hline Años & Mujeres & Hombres & $\begin{array}{c}\text { Mujeres } \\
\text { menores }\end{array}$ & $\begin{array}{c}\text { Hombres } \\
\text { menores }\end{array}$ & TOTAL \\
\hline 2014 & & & & & $173^{*}$ \\
\hline 2015 & 19 & 92 & & & 111 \\
\hline 2016 & 13 & 71 & 2 & & 86 \\
\hline 2017 & 33 & 35 & 1 & & 69 \\
\hline
\end{tabular}

Fuente: Memoria Fiscalía General del Estado.

* No aparecen en la Memoria desglosados

Se ha mencionado que la trata con fines de explotación laboral presenta mayor volumen a nivel mundial, tal y como la administración Obama puso de relieve (US Departamento de Estado, 2010) $)^{5}$ y la Organización Internacional del Trabajo $(\mathrm{OIT}, 2012)^{6}$, pero en las estadísticas oficiales resulta más reducida que la trata con fines de explotación sexual. ¿Por qué se identifican más víctimas con finalidad sexual que laboral? ¿no estará eclipsando la trata con fines de explotación sexual a la laboral? ¿Qué dificultades entraña la identificación en ambos tipos de explotación? El último informe GRETA se recomendaba a España mejorar la identificación y asistencia a las víctimas de trata con fines de explotación laboral, además

\footnotetext{
${ }^{5}$ https://www.state.gov/documents/organization/142979.pdf

${ }^{6} \mathrm{http}: / /$ www.ilo.org/global/about-the-ilo/newsroom/news/WCMS_181961/lang--en/index.htm (consulta 20 diciembre 2018).
} 
de ofrecer recomendaciones para visibilizar, prevenir y perseguir este delito en los sectores laborales más proclives (GRETA, 2018). Además, nos surgen otras preguntas. Con los esfuerzos que se vienen desarrollando en los últimos años ¿están subestimadas las personas identificadas como víctimas? ¿Estamos fallando en la detección de estas personas? ¿Qué circunstancias influyen en una baja identificación? Intentaremos reflexionar en este espacio sobre estas cuestiones partiendo de los datos publicados y estudios realizados. Entendemos que las dificultades que podemos encontrar pueden ser de tres tipos: el primero está relacionado con los conceptos que se manejan en este fenómeno social, que resultan en muchas ocasiones ambiguos y necesitan cierta clarificación; el segundo con las dificultades que las propias víctimas poseen y que impiden en ocasiones detectarlas, identificarlas y rescatarlas, si este concepto es aplicable. El tercer tipo se refiere a aquellos obstáculos que deben afrontar las instituciones, los profesionales e incluso la propia sociedad. Reflexionaremos sobre cada uno de ellos.

\section{SITUACIONES DIFERENTES QUE DIFICULTAN LA IDENTIFICACIÓN}

En muchas ocasiones se confunden algunos conceptos que están relacionados y que conllevan realidades distintas. En este sentido debe distinguirse la trata del tráfico de personas, la prostitución de la trata, la explotación sexual de la económica, el abuso y explotación laboral de la trata con fines de explotación laboral (Surtees, 2008). La escasez de estadísticas de cada una de estas realidades y el tratamiento jurídico de las mismas, que difiere de la realidad social o sociológica, suponen que los límites entre estos hechos sean difusos en muchas ocasiones y fuente de confusión (Piscitelli, 2012; Allain, 2019). Por otra parte, el delito de trata resulta difícil de probar, produciéndose en muchas ocasiones el archivo de las causas (Meneses et al., 2015).

La trata, el tráfico y la explotación sexual de mujeres están relacionadas con situaciones vitales precarias y vulnerables en muchos países. Las grandes desigualdades sociales y económicas a nivel mundial han incrementado los procesos migratorios desde los países en desarrollo hacía países industrializados, con el objetivo de conseguir más altos niveles de bienestar personal y social. No solo se persigue mejorar las condiciones de vida sino la seguridad vital. Esto hace emprender el camino de millones de personas hacia los centros de seguridad y bienestar económico, que por otra parte cierran sus fronteras con leyes que pretenden regular esos flujos migratorios.

Centrándonos en la clarificación de conceptos, y tal como lo define el Protocolo de Palermo, en el artículo 3 en el punto a: 


\section{Carmen Meneses Falcón}

Por "trata de personas" se entenderá la captación, el transporte, el traslado, la acogida o la recepción de personas, recurriendo a la amenaza o al uso de la fuerza u otras formas de coacción, al rapto, al fraude, al engaño, al abuso de poder o de una situación de vulnerabilidad o a la concesión o recepción de pagos o beneficios para obtener el consentimiento de una persona que tenga autoridad sobre otra, con fines de explotación. Esa explotación incluirá, como mínimo, la explotación de la prostitución ajena u otras formas de explotación sexual, los trabajos o servicios forzados, la esclavitud o las prácticas análogas a la esclavitud, la servidumbre o la extracción de órganos?

Quien ejerce esta acción es un tratante, o una red de tratantes, con una serie de características comunes con las víctimas, que es lo que facilita la captación y el engaño (Surtees, 2008). En la siguiente cita lo comentaba una de las víctimas entrevistada en una investigación realizada (Meneses et al., 2015):

"Entonces, he estado siempre en la calle y... al cumplir 18 años encontré a una persona, que me indicó a otra, me vendió la mafia y, entonces, la mafia me trajo aquí con unas promesas... que no cumplieron.(...) Sabia que venía a la prostitución, pero sabía que... exactamente prostitución no, es que... hacer compañía a la gente, y que si quería sí podría acostarme con ellos, si no quería pues, pues no pasa nada, pero que... no era así, porque cuando llegue aquí, cuando empecé a negar acostarme con las personas, entonces empezaron a pegarme, a maltratarme" (Mujer búlgara, 21 años) ${ }^{8}$.

En la trata por tanto concurren una serie de circunstancias donde el engaño y la violencia suelen estar presentes sobre todo al comienzo de su expansión como delito, pues las formas de coerción pueden ser físicas, pero también psicológicas, que a veces son más efectivas. El siguiente concepto es el de tráfico ilegal de personas, que es definido en el Protocolo contra el Tráfico Ilícito de Migrantes por tierra, mar y aire de Naciones Unidas, en el artículo 3, puntos a y b:

a) Por "tráfico ilícito de migrantes" se entenderá la facilitación de la entrada ilegal de una persona en un Estado Parte del cual dicha persona no sea nacional o residente permanente con el fin de obtener, directa o indirectamente, un beneficio financiero u otro beneficio de orden material; b) Por "entrada ilegal" se entenderá el paso de fronteras sin haber cumplido los requisitos necesarios para entrar legalmente en el Estado receptor ${ }^{9}$.

${ }^{7}$ http://www.unodc.org/documents/treaties/UNTOC/Publications/TOC\%20Convention/TOCebook-s.pdf, p. 44.

${ }^{8}$ Entrevista realizada en la investigación "Apoyando a las víctimas de trata" en el 2015, véase en las referencias bibliográficas.

${ }^{9}$ http://www.unodc.org/documents/treaties/UNTOC/Publications/TOC\%20Convention/TOCebook-s.pdf, p. 57. 
Cuando una persona comprueba que los requisitos que le exigen las leyes migratorias europeas no los puede cumplir ${ }^{10}$ averiguará la manera de poder emprender el proyecto migratorio eludiendo estos requerimientos. Para ello puede buscar alguna red de personas (traficantes) que le facilite ese traslado por cierto coste económico; o puede que su familia le ofrezca los recursos económicos que necesita para emprender el viaje con algún contacto en el país de destino; o en ocasiones recibirá una oferta de alguien en su propio país sobre un posible trabajo en España, también a cambio de un dinero (Surtees, 2008; Piscitelli, 2012). En estos casos no existe coerción, secuestro, amenazas ni explotación de una actividad. En estos casos una persona, o una red de personas, le ayudará por una cuantía de dinero a atravesar una frontera y establecerse en otro país, que por ella misma o no puede o le resulta complicado hacerlo. En nuestra legislación es el articulo 318 bis, en los puntos 1 y 2, del Código Penal el que contempla el delito de tráfico de personas, o Delito contra el Derecho de los Ciudadanos Extranjeros:

1. El que intencionadamente ayude a una persona que no sea nacional de un Estado miembro de la Unión Europea a entrar en territorio español o a transitar a través del mismo de un modo que vulnere la legislación sobre entrada o tránsito de extranjeros, será castigado con una pena de multa de tres a doce meses o prisión de tres meses a un año. Los hechos no serán punibles cuando el objetivo perseguido por el autor fuere únicamente prestar ayuda humanitaria a la persona de que se trate. Si los hechos se hubieran cometido con ánimo de lucro se impondrá la pena en su mitad superior. 2. El que intencionadamente ayude, con ánimo de lucro, a una persona que no sea nacional de un Estado miembro de la Unión Europea a permanecer en España, vulnerando la legislación sobre estancia de extranjeros será castigado con una pena de multa de tres a doce meses o prisión de tres meses a un año.

El traficante solo ayuda a cruzar la frontera y ahí suele acabar su implicación. $\mathrm{Si}$ bien es cierto que las dos situaciones son distintas, en ocasiones lo que comienza como tráfico ilícito de inmigrantes acaba convirtiéndose en trata de personas, por las conexiones que entre las redes existen y la demora en sufragar las deudas contraídas (Ventrella, 2017). Los fiscales serán uno de los juristas que cotidianamente deben distinguir estos dos delitos, sobre todo porque la trata tiene una alta penalidad frente al tráfico de personas, cuya pena es inferior. La siguiente cita corresponde a uno de los fiscales de trata extranjería que ha sido entrevistado en los últimos años en el estudio Meneses et al. (2015).

${ }^{10}$ Pasaporte, VISA otorgada por el país de destino, una cantidad de dinero, una invitación u oferta de trabajo. 


\section{Carmen Meneses Falcón}

Unas chicas de Latinoamérica que sabían que venían a prostituirse. Eso no tiene nada que ver, cabe la posibilidad de que haya una trata a pesar de que tú sepas que vienes a prostituirte. Hay casos en que es complicado decidirlo. Pero una de las cinco que vinieron no quería prostituirse, pero la obligaron y la amenazaban ahí habría. Venían cinco y cuatro de ellas venían a prostituirse y además, pasaron de la tratante en el sentido de "yo me prostituyo como quiero y ya te lo iré pagando. Pero déjame a mí controlar mis horarios y mis clientes". Le pedían 4000 euros a cada uno. Se calificó como inmigración ilegal porque las condiciones las fijaban ellas. Es decir, al final se convirtió únicamente en una deuda, absolutamente desproporcionada en relación al billete que se paga. En el caso de una de ellas vino pensando que venía a trabajar en el servicio doméstico y se vio obligada, además se la veía completamente destrozada, a ejercer la prostitución obligada por la misma tratante, pero con las otras no pudo con ellas ${ }^{11}$.

Muchas veces la realidad es más compleja, como se puede apreciar en la nota anterior, y sobre todo es necesario pruebas para imputar el delito, especialmente el de trata que es un delito contra las personas mientras que el tráfico es un delito contra el Estado. Por tanto, trata y tráfico son diferentes respecto a la situación de la víctima y a la implicación y forma de actuar de los tratantes o traficantes (O'Connell, 2010).

Otro concepto que necesita ser clarificado es la distinción entre trata y prostitución. La trata con fines de explotación sexual es una forma de prostitución coactiva, pero no toda la prostitución es forzada. En ocasiones, algunas noticias difundidas en los medios de comunicación han planteado que toda la prostitución es trata, o que la gran mayoría de la prostitución es por trata ${ }^{12}$, sin justificar y documentar dichas afirmaciones. En primer lugar, se desconoce el número de personas que ejerce la prostitución en España y no hay ningún estudio que en los últimos años lo haya estimado ${ }^{13}$. La cifra que se ofrece en el Plan Integral contra la Trata, antes mencionado, tiene su origen en fuentes policiales que no refleja toda la realidad social existente. En segundo lugar, no existen datos ni estimaciones que determinen cuántas mujeres de las que ejercen la prostitución son víctimas de trata, y las que se han realizado arrojan cifras muy bajas (Steinfatt y Baker, 2011; Meneses 2019). Resulta muy difícil aceptar que haya mujeres que toman la decisión de realizar esta actividad y que la acepten sin que sean coaccionadas,

${ }^{11}$ Entrevista realizada en el marco de la investigación Apoyando a las víctimas de trata, 2015. Véase referencias bibliográficas finales.

12 ABC (2015, 18 septiembre) https://www.abc.es/sociedad/20150918/abci-mujeres-obligadas-prostitucion-201509181643.html, y Europa Press (2016, 16 agosto) https://www.europapress.es/epsocial/cooperacion-desarrollo/noticia-90-ciento-mujeres-prostitutas-espana-son-victimas-esclavitud-siglo-xxi-denuncia-mabel-lozano-20100722152142.html

${ }^{13}$ El último es de Malgesini en el 2005. 
forzadas o inducidas a ello. Socialmente se entiende que quien vende su cuerpo por dinero solo puede hacerlo porque es víctima de trata, de violencia o ha sido inducida a ello, por mencionar algunas de las razones (Juliano, 2004). La cuestión subyacente es la propia consideración de la prostitución. Mientras que para un sector de las feministas, intelectuales o políticos es una forma de violencia de género, cuyas raíces se encuentra en la centralidad de la sexualidad masculina propia de la sociedad patriarcal (de Miguel, 2014), para otro, es un modo más de conseguir recursos económicos disponible en las mujeres, puesto que poseen más capital erótico que los hombres y lo aprovechan (Hakin, 2019); sin embargo, no podemos olvidar que aunque cuantitativamente sean muchos menos, las transgénero y los hombres recurren a esta actividad en ocasiones (Juliano, 2002; Agustín, 2004). Las mujeres no son irracionales ni menores de edad y en momento determinados toman decisiones racionales que pueden no ser las que la sociedad mayoritaria considera socialmente admitidas. Si bien es cierto que las personas que se dedican a la prostitución en todos los países industrializados son una minoría con respecto a la población general, quizás no se requiera una legislación específica que la regule, pero tampoco una legislación que la criminalice directa o indirectamente, sobre todo porque esto tendrá consecuencias para las que son víctimas (Villacampa, 2017). Las legislaciones que criminalizan la prostitución solo consiguen hacerla más clandestina con importantes repercusiones negativas desde el punto de vista social y de salud en las mujeres más vulnerables, como algunos informes han planteado de la reciente legislación prohibitiva francesa ${ }^{14}$. En definitiva, existe un sector de personas, predominantemente mujeres, que ejerce la prostitución por decisión propia y sin coacción, porque consigue recursos económicos más altos que de otra manera no los lograría, y ocultarlo o negarlo sería no querer ver una realidad que puede comprobar cualquiera. No podemos igualar la trata a la prostitución por decisión propia, y asimilar ambos conceptos conlleva consecuencias negativas para las mujeres. Cabe recordar que la prostitución coactiva o forzada está castigada en el CP en el artículo 188, entendiendo que el que obligue a ejercer o mantenerse en la actividad será castigado con penas de dos a cuatro años. No es delito si alguien favorece la prostitución de personas que la ejercen de manera voluntaria y es la razón de la existencia de distintos negocios sobre los servicios sexuales en España ${ }^{15}$. En cambio, si es un delito la inducción o la coacción para mantenerse en la prostitución. Estos delitos también son complicados de demostrar.

14 Véase https://www.opendemocracy.net/en/beyond-trafficking-and-slavery/searching-for-the-entranceto-frances-prostitution-exit-programme/

${ }^{15}$ Es el caso de los clubs de alterne, sus dueños se denominan hosteleros porque ellos alquilan habitaciones y ofrecen un bar de alterne, pero no se meten en los negocios sexuales que las mujeres que están en sus locales realizan. Si bien es cierto que esto es lo que se dice, no siempre es lo que se hace.

icade. Revista cuatrimestral de las Facultades de Derecho y Ciencias Económicas y Empresariales, $n^{\circ} 107$ mayo-agosto 2019, ISSN: 2341-0841 
Otro concepto que se confunde en muchas ocasiones es la explotación sexual y la explotación económica en la prestación de actividades sexuales (Piscitelli, 2012), pero el Código Penal no hace esta distinción. En el artículo 187, punto 1, indica que:

1. El que, empleando violencia, intimidación o engaño, o abusando de una situación de superioridad o de necesidad o vulnerabilidad de la víctima, determine a una persona mayor de edad a ejercer o a mantenerse en la prostitución, será castigado con las penas de prisión de dos a cinco años y multa de doce a veinticuatro meses. Se impondrá la pena de prisión de dos a cuatro años y multa de doce a veinticuatro meses a quien se lucre explotando la prostitución de otra persona, aun con el consentimiento de la misma. En todo caso, se entenderá que hay explotación cuando concurra alguna de las siguientes circunstancias: a) Que la víctima se encuentre en una situación de vulnerabilidad personal o económica. b) Que se le impongan para su ejercicio condiciones gravosas, desproporcionadas o abusivas.

¿Qué significa ejercicio de condiciones gravosas, desproporcionadas o abusivas? Dado que no existe ninguna regulación sobre la actividad prostitucional queda sujeto a lo que considere como tal la policía, la fiscalía o el juez instructor. Por tanto, las condiciones de explotación recogidas en el Código Penal no están detalladas, generando una situación de ambigüedad y de interpretación subjetiva (Lima de Pérez, 2015). Cuando observamos la realidad social esto puede ser algo más claro, sobre todo si preguntamos a las mujeres que ejercen la prostitución que entienden por explotación. Se distingue la explotación sexual de la económica porque la primera se realiza sin consentimiento, es decir, existe explotación sexual cuando el ejercicio de la prostitución es forzado (Piscitelli, 2012), hablamos de explotación sexual en los casos de trata. Pero cuando la prostitución no es forzada, sino que es decida por las personas que la ejercen, entonces las propias mujeres lo entienden como explotación económica. Así fue recogido en una entrevista a una de las mujeres que ejercía la prostitución en una ciudad española en el marco de una investigación (Meneses et al., 2019).

"Yo he trabajado en piso, el piso ya en sí es un abuso, porque trabajas a 60/40 o a 50/50. En el club, tú tienes que dar como un 10\% de lo que tú haces, de tus servicios, pero en un piso ya es un robo, ya es un atraco. Tienes que pillar con alguien que haya sido compañera tuya, o de repente te haces un poco coleguita, o lo que sea, sino es un abuso, si te vas a un piso por ahí, te cobran. ¡Vamos!, las sábanas, los condones, más el 50\% de tu chocho, ¡Vamos!, una ruina. Y es voluntario, porque tú vas sabiendo lo que es esto, pero te están explotando, y muchas veces da mucha pena porque hay muchas mujeres y hombres, bueno, hombres menos. Luego son pisos en los que no tienes horario, igual acabas de hacer un servicio a las 4 de la mañana y a las 9 de la mañana 
te están llamando para otro, con lo cual, tú vas 15 o 20 días, pero no puedes dormir" (Mujer que ejerce la prostitución, dominicana, 43 años) ${ }^{16}$.

Las mujeres entrevistadas no tenían otra opción que compartir sus ingresos económicos de la prostitución con los dueños y dueñas de los pisos dedicados a esta actividad, pero eso no significaba que el descuento o aportación que se hacía no lo percibieran como un abuso. Ellas no podían crearse la infraestructura que estos pisos tenían y sentían que les cobraban excesivamente para poder ofrecer sus servicios en ellos. Las mujeres percibían estas deducciones como explotación económica derivada del ejercicio voluntario de la prostitución, porque las condiciones que les imponían y tenían que aceptar les parecían abusivas. Otra opción para evitar compartir sus ingresos de la prostitución era ejercerla en la calle, en zonas no controladas por las mafias ${ }^{17}$, pero debían enfrentarse a tres problemas: las sanciones económicas por situarse en la vía pública por parte de la policía, una mayor probabilidad de violencia y agresiones por partes de clientes o grupos incontrolados y, por último, los controles de extranjería con la posible deportación si no se poseía la documentación requerida para residir en España. La gran mayoría de las personas que ejercen la prostitución en España es extranjera y ha sido puesto de relieve en distintos trabajos (Malguesini, 2006; Sanchis \& Serra, 2011). Una chica española entrevistada lo verbalizaba de esta manera en uno de los estudios mencionados:

"He tenido de todas agresiones fuertes y han sido en la calle, me han quitado todo lo que he cobrado, me han quitado lo que me han regalado, todo, y luego me han dejado, llena de barro, de mierda y llena de moratones de patadas" (Española, 37 años) ${ }^{18}$.

Por último, otros dos conceptos que generan confusión son la explotación laboral y la trata con fines de explotación laboral. Si bien es cierto que la simple explotación laboral podría distinguirse mejor porque existe una normativa de los derechos y deberes para los trabajadores, en general y en cada sector laboral, cuando nos centramos en trabajadores inmigrantes, y más si son irregulares, estos conceptos se hacen más complejos. La explotación laboral puede tener múltiples situaciones, pudiéndose distinguir una graduación de condiciones laborales que se podrían calificar como explotación sin que haya una línea divisoria clara. Se trata

${ }^{16}$ Entrevista realizada en la Investigación: Meneses et al. La trata de mujeres y niñas con fines de explotación sexual en Euskadi, 2019. EMAKUDE. Informe no publicado.

17 Diarios de campo de Observación Participante en los polígonos industriales que ejercen la prostitución de Marconi en Madrid, Alfalfar en Valencia y Guadalhorce en Málaga, realizados entre 2015 y 2017. Las redes de mafiosos instaladas que controlan los espacios exigen un dinero semanal por ocupar uno de estos espacios públicos.

${ }^{18}$ Entrevista realizada en el marco de la investigación Apoyando a las víctimas de trata, 2015. 


\section{Carmen Meneses Falcón}

de un continuum desde el abuso, a la explotación y finalizando en el trabajo forzoso (ACCEM, 2008). La trata con esta finalidad se refiere al trabajo forzoso, más en sintonía con los siglos en los que la esclavitud era vigente. Thieman (2016) señala que la línea que separa la migración voluntaria de la trata es tenue porque la explotación y la vulnerabilidad de las situaciones laborales de estos trabajadores es un continuum más que categorías diferenciadas. De nuevo no queda claro ni recogida las conductas que pueden suponer trabajo forzoso, o condiciones de esclavitud (Pomares, 2011), y lo que sucede es que en la mayoría de los casos se aplica los artículos 311 y 312 del CP, de Delitos contra el Derecho de los Trabajadores. Estos plantean

Artículo 311. Serán castigados con las penas de prisión de seis meses a seis años y multa de seis a doce meses: $1 .^{\circ}$ Los que, mediante engaño o abuso de situación de necesidad, impongan a los trabajadores a su servicio condiciones laborales o de Seguridad Social que perjudiquen, supriman o restrinjan los derechos que tengan reconocidos por disposiciones legales, convenios colectivos o contrato individual. 2. ${ }^{\circ}$ Los que den ocupación simultáneamente a una pluralidad de trabajadores sin comunicar su alta en el régimen de la Seguridad Social que corresponda o, en su caso, sin haber obtenido la correspondiente autorización de trabajo, (...).

Artículo 312.1. Serán castigados con las penas de prisión de dos a cinco años y multa de seis a doce meses, los que trafiquen de manera ilegal con mano de obra. 2. En la misma pena incurrirán quienes recluten personas o las determinen a abandonar su puesto de trabajo ofreciendo empleo o condiciones de trabajo engañosas o falsas, y quienes empleen a súbditos extranjeros sin permiso de trabajo en condiciones que perjudiquen, supriman o restrinjan los derechos que tuviesen reconocidos por disposiciones legales, convenios colectivos o contrato individual (...)

En los casos estudiados en Meneses, Urío y Uroz (2019) se producía la captación de personas para desarrollar un trabajo en España en sectores como el textil, la agricultura o el servicio doméstico ${ }^{19}$ como una oferta mucho mejor que las que encontraban en sus propios países. El engaño acontecía cuando las condiciones de trabajo que en el momento de la captación se describieron no correspondían con las que se encontraron posteriormente en el destino, en este caso en España. Además, se unía otra serie de conductas que a veces no eran fáciles de probar porque el captador de los trabajadores solía ser de mismo país de origen que las víctimas, -tenía la misma nacionalidad y solía ser conocidos, familiares o vecinos-, y a su vez estos eran los capataces de los empresarios de los sectores laborales descritos. Así lo comunicaron los miembros de los cuerpos policiales entrevistados en el estudio citado.

19 Son sectores con mercados precarios, condiciones laborales escasas y salarios muy bajos. 
"Generalmente, los negritos y los hombres que buscan trabajo están en la plaza del pueblo (carne humana, como la llaman) y pasa el manijero o capataz con la furgoneta y recoge a los que necesitan para la finca o la explotación agrícola. Generalmente es delito contra los trabajadores y de extranjeros, es decir, explotación laboral, es muy difícil probar la trata. Además, la legislación permite que en el día que contrastas no le des de alta hasta las 12.00, con lo cual puede estar trabajando desde muy temprano y no ser dado de alta y trabajar sin seguridad social" (PN Huelva, 2017) 20 .

"Víctimas de origen rumano y polaco, y sus captores suelen ser rumanos. Contrata a veces en el país de origen y le traen para el sector agrario (fresa y cítricos). El empresario contrata al trabajador, al manijero o capataz, y este es el que se encarga de reclutar, captar a la cuadrilla de hombres para recoger los productos. El empresario puede estar informado o no, no suele estarlo, pero le da igual en las condiciones que trabajan los trabajadores. Tanto el manijero como el empresario solo buscan el beneficio. La legislación facilita muchas veces esa explotación, al poder dar de alta en el mismo día y hasta las 12 horas. A raíz de una muerte laboral, pudieron ver como transportaban a los trabajadores en un remolque con sillas que estaban sujetas con cadenas o tornillos" (GC, Huelva, 2017) ${ }^{19}$

En muchas ocasiones no recibían un salario, trabajaban en condiciones insalubres y degradantes, con largas horas de trabajo y sin descanso, teniendo que poner ellos en ocasiones el material de trabajo, y no estaban dados de alta en la seguridad social. Estas condiciones laborales de explotación pasaron desapercibidas, porque estos trabajadores no denunciaban al encontrarse de manera irregular en España. La mayoría aceptaba las condiciones de esclavitud a cambio de un dinero -que en España era considerado muy poco dinero pero en sus países de origen suponía un monto considerable-, y a los capataces y empresarios les interesaba el lucro que obtenían de esta explotación (Meneses, Urío \& Uroz, 2019).

En definitiva, no es solo tener claro la distinción entre los conceptos expuestos, sino que además se debe analizar adecuadamente una realidad social compleja y disponer de pruebas para perseguir y aplicar el delito correcto en la instrucción, así como en la investigación social. La falta de claridad y distinción en todas las situaciones descritas anteriormente puede dificultar la aplicación adecuada de la atención y protección a las personas víctimas de trata, especialmente a las mujeres con mayor vulnerabilidad, tal y como ha puesto de relieve Noyori-Corbett y Moxley (2017).

${ }^{20}$ Entrevista realizada en la investigación: Financing of Trafficking in Human Beings in Spain, véase en las referencias bibliográficas finales. 


\section{DIFICULTADES DESDE LAS VÍCTIMAS}

Salvo las personas que provienen de países de la Unión Europea, donde el tráfico de personas no tiene sentido, en el resto de los países las mujeres y hombres que emprenden una trayectoria migratoria saben que tendrán que cumplir los requisitos que se exigen en la UE para entrar y residir dentro de su territorio. Muchas mujeres no consiguen la visa o los requerimientos establecidos y por ello recurren a redes de trata o tráfico, o a la oferta de persona o familiares que ya están establecidos dentro de la UE para venir a España. Una primera cuestión que dificulta la posible identificación de estas personas tratadas o traficadas es que no se reconocen como víctimas por muchas razones.

En primer lugar, porque consideran que las consecuencias negativas que han acontecido en esa trayectoria migratoria se deben a que quizás no hayan negociado adecuadamente el viaje, surgiendo el sentimiento de culpa y la inevitabilidad del destino. Perciben que ellas han hecho un pacto con personas que le han ayudado a emprender una nueva situación en su vida y que deben cumplir lo acordado, a pesar de que la deuda contraída sea abusiva y la manera de devolverlo también.

En segundo lugar, muchas de estas personas no se documentan previamente sobre las leyes, normativas y derechos que rigen en el país de destino. Desconocen que la situación que pueden estar viviendo sea un delito y que sea víctima del mismo. Además, si el idioma es distinto al suyo se encontrará que no podrá comunicarse con nadie excepto con sus paisanos que son los que le han facilitado la entrada y su explotación. Así, el aislamiento, el desconocimiento de la normativa del país de destino y del idioma le conducen a no comunicar la situación que vive.

En tercer lugar, estarán muy agradecidas a las redes de tratantes, que son paisanos suyos, por facilitarles el transito migratorio y una oportunidad en un país con mayor bienestar del que procede (Alomar \& Plasencia, 2014). Confiaran en ellos más que en aquellas personas que puedan acercarse a ella, por lo menos durante primer año. Los tratantes le darán informaciones falsas sobre el país de destino y especialmente sobre la policía española. Si la experiencia que estas víctimas tienen en sus países de origen es de la existencia de corrupción policial, los tratantes se encargarán de convencer a las víctimas de que la policía española es similar.

En cuarto lugar, su condición de inmigrante irregular le impedirá denunciar, pues al hacerlo podría salir de la propia comisaria con una orden de expulsión, sobre todo si no aporta suficiente información que pueda probar que es víctima del delito de trata. Además, como la policía española realiza controles de documentación de extranjería, abriendo expedientes a quienes no la tiene correcta y vigente, e incluso produciéndose el internamiento en los CIE, se cumple lo que le han dicho sus tratantes, o han observado en otras mujeres de su misma nacionalidad, de nuevo evitando la denuncia. Dependiendo de las condiciones de explotación 
y del país de origen, preferirá continuar con la situación de explotación que denunciarla. Solo cuando se hace insostenible dicha situación, o empieza a confiar en personas autóctonas que le describen otra realidad, es cuando puede ser consciente de su situación de víctima. Pero para esto por desgracia puede que pasen meses o incluso algunos años.

Por último, muchas víctimas, aunque desconozcan sus derechos, son conscientes que están abusando de ellas, del engaño al que han sido sometido y las amenazas y violencia que están sufriendo por parte de los tratantes. Estos le han amenazado con hacerle daño a ella, a sus hijos o a sus familiares (Alomar \& Plasencia, 2014). El miedo a que esto ocurra, pues en ocasiones han visto como han actuado con otras víctimas, les impide denunciar la situación. También algunos aspectos culturales implicados actúan inhibiendo la denuncia por las repercusiones que pueden conllevarle. La utilización de rituales mágico-religiosos sirve para sellar el pacto y deuda contraído con los tratantes, que incluye no denunciar ni hablar con la policía.

No he agotado todas las dificultades que desde las victimas podemos hallar, me he referido a las más relevantes y frecuentes que dificultan la identificación. Si ellas mismas no se reconocen como tales, cómo lo van a hacer los profesionales y las entidades en relación con ellas. Esta es una de las cuestiones difíciles de abordar, salvo desde la prevención e información en los países de origen. Muchas de estas descripciones son comunes para las víctimas de trata con fines de explotación sexual como laboral, aunque de esta última tenemos menos estudios para documentarlo.

\section{DIFICULTADES DESDE LAS INSTITUCIONES}

En los contextos de prostitución existen ONGs que vienen desarrollando una labor sociosanitaria con las personas que se prostituyen y sus profesionales están capacitados para la detección de aquellas mujeres que pueden ser víctimas ${ }^{21}$. Las relaciones estrechas y de confianza que se crean entre los miembros de las ONGs y las mujeres que están en estos contextos generan una situación privilegiada para la detección. Sin embargo, en los sectores laborales donde puede surgir situaciones de trata existen menos asociaciones y colectivos en contacto con los trabajadores de estos sectores precarios, siendo más difícil esa detección. No obstante, una cuestión es detectar una posible victima en función de una serie de indicadores sociales y otra la identificación legal de la misma, que suele ser competencia de los

21 Véase las Memorias del trabajo desarrollado en los últimos años por Médicos del mundo, cuyo trabajo en contextos de prostitución detectan alrededor del $9 \%$ de posibles víctimas de trata. 


\section{Carmen Meneses Falcón}

cuerpos policiales. La identificación de las víctimas en el ordenamiento jurídico español significa que estas mujeres denuncien la situación sufrida, y a sus tratantes. Porque si no hay denuncia no hay delito y no hay víctima identificada, y eso a pesar de que son muchas las directivas europeas, propósitos de las autoridades y recomendaciones planteadas. Así nos lo han manifestado en diversos estudios algunos miembros de la fiscalía, la policía o la judicatura.

"Si no hay víctima, no hay delito... pero es que claro, sin una víctima que te diga "sí, efectivamente, a mí me ha pasado esto", es muy difícil condenar a una persona..." (Juez, Madrid) 22 .

"El problema es: primero, queramos o no, es un delito que afecta a bien jurídico eminentemente personal, donde normalmente la prueba reina esencial va a ser la declaración de la propia víctima. ¡Imagínate una agresión sexual sin la víctima...! Pues tienes problemas..." (Fiscal, Barcelona) ${ }^{23}$.

"No se puede decir en un Protocolo que no es necesario que la víctima declare, no es necesario que la víctima colabore, no es necesario que no sé qué...para que tenga la protección desde el punto de vista social, me parece estupendísimo, pero todo esto, desde el punto de vista judicial, no vale para nada. Si la víctima no mantiene su tesis, si no permanece aquí bajo protección nuestra, si no declara no vale para nada porque tenemos un procedimiento penal determinado" (Policía Asturias) ${ }^{24}$.

El sistema jurídico español da garantías a los detenidos para evitar las denuncias falsas y se necesita que las víctimas realicen una acusación para que se pueda investigar los hechos. Las víctimas podrán hacerlo en la medida que sus derechos y protección estén garantizados y estas situaciones son difíciles de acometer, sobre todo cuando los amenazados son sus hijos o familiares en sus países de origen, que no pueden recibir una protección directa.

Mientras que la detección de una víctima de trata es posible que sea realizado por cualquier profesional, por un cliente, o por un ciudadano que esté atento, en base a unos indicadores, la identificación, como mencionamos antes, la realiza los cuerpos policiales. Esto genera muchos problemas y las fuerzas de seguridad son conscientes de ello. Las víctimas no van a querer hablar con la policía por muchos motivos, principalmente porque se sienten intimidadas. Pero, además, la policía suele centrarse en la investigación del delito y aunque pueda estar sensible y atenta a las necesidades de las víctimas, los cuerpos policiales no son las personas de confianza para ellas, por la experiencia que poseen en sus países. En ocasiones

${ }^{22}$ Entrevista procedente del estudio: "Difficulties in trying and judging crimes of trafficking for the purpose of sexual exploitation in Spain: the judges' view” en prensa.

${ }^{23}$ Entrevista perteneciente a la investigación Apoyando a las víctimas de trata.

24 Ídem. 
la propia policía recibe la colaboración de miembros de las ONGs que le ayuda a realizar esa identificación. Sin embargo, el Estado y la administración pública son los que deben tener los mecanismos adecuados para realizar esta tarea. En este sentido, para ser más eficaces se debería crear una estructura estable adecuada y preparada para atender e identificar a las víctimas, así como prestarle la cobertura y recursos que necesiten. Por una parte, la presencia y asistencia de un abogado que vele por sus derechos y protección en todo el proceso policial y judicial ${ }^{25}$ es otra posibilidad a considerar, como sucede con las víctimas de violencia de género. Un equipo psicosocial de la administración pública debería ser el encargado de gestionar la asistencia a las víctimas, la valoración de los recursos que necesita, la solicitud de protección, el tipo de protección que precisa y todo aquello que requiera para su bienestar. De tal forma que se encargará desde que se detecta una persona como posible víctima hasta que se recupere de las consecuencias negativas sufridas, o se facilite su repatriación a su país si es su deseo. Las valoraciones sobre el riesgo que estas personas corren por parte de sus tratantes son elaboradas actualmente por la policía, pero este equipo psicosocial podrá aportar otro punto de vista desde las características psicosociales de cada una de las víctimas.

Otro aspecto importante que precisa atención y mejora es la coordinación de los profesionales que trabajan directamente con las posibles víctimas, especialmente cuando ya son identificadas. Si actualmente existen mecanismos de coordinación en las instituciones y administraciones, donde están representados muchos de los agentes sociales intervinientes, se requiere un mayor esfuerzo en los niveles de intervención de base: a) mejor cooperación, colaboración y coordinación entre los cuerpos policiales, b) entre éstos y las ONGs, c) entre las propias ONGs que intervienen directa o indirectamente en contextos donde podría existir alguna víctima y los profesionales de distintas áreas sociosanitarias, es decir, estos aspectos requieren revisión y mejoras. La competencia por la intervención y el protagonismo impiden en ocasiones avanzar más de lo que se podría. Por otra parte, resulta muy gratificante el rescate de víctimas de trata, pues en décadas pasadas algunas de estas mujeres vivieron verdaderas situaciones de esclavitud. Posteriormente, las formas de dominio sobre las víctimas se han ido modificado, principalmente como una estrategia de los tratantes para no ser descubiertos y detenidos. Para muchos profesionales que llevan años trabajando en contextos de exclusión social y ámbitos de prostitución, que suelen ser poco valorados socialmente, ocuparse en la detección y rescate de las víctimas de trata con fines de explotación social supone un mayor reconocimiento social. De hecho, las subvenciones destinadas a intervenir en los contextos de prostitución eran escasas

25 En algunas ciudades españolas existe un turno de oficio para atender víctimas de trata desde los colegios de abogados. Es el caso de Madrid, Sevilla o Málaga. 
con anterioridad e inexistentes específicamente. Con el surgimiento de la trata para la explotación sexual existe una partida anual como hemos mencionado al comienzo. La gratificación a nivel personal y social para trabajar con estas personas no debería bloquear el trabajo en red, porque solo de esa manera se podrá conseguir mejores resultados.

En la detección es posible la participación de algunos profesionales no especializados y población general, ya que no es exclusivo de profesionales especializados (Gordon, 2018). Para que surja esta oportunidad se requiere sensibilización y formación de estos profesionales, e incluso de la población, pues un mayor conocimiento aumentará esta tarea (Villacampa \& Torres, 2017). Las situaciones de trata con fines de explotación laboral pueden estar cerca de cualquiera (por ejemplo, el servicio doméstico). En el caso de la explotación sexual serán los hombres que pagan por servicios sexuales los primeros en encontrarse con una víctima. Si en ambos casos se posee la concienciación y el conocimiento sobre los indicios y condiciones que pueden vivir estas personas será más fácil esa detección. No se trata de que el ciudadano que sospeche de que alguien está siendo explotada contra su voluntad rescate a esa persona, porque puede ponerla en peligro. La policía dispone de un teléfono de recogida de atención y sabe cómo se debe intervenir. En el caso de los profesionales no especializados, como pueden ser los sanitarios, los trabajadores sociales de otras áreas, los funcionarios públicos, etc., para que puedan abordar esa labor de detección necesitan más formación sobre los indicadores de trata de seres humanos. Los profesionales que trabajan en la intervención social, pública o privada, entran en contacto con personas muy diversas, y en algunos casos tienen un estrecho contacto con población inmigrante, pudiendo identificar a posibles víctimas.

Por último, la criminalización y estigmatización de ciertos colectivos, como las mujeres que ejercen la prostitución o los inmigrantes en situación irregular, inciden negativamente en la posibilidad de comunicar y denunciar la situación de trata. De estas dos situaciones nos centramos en una, las sanciones administrativas por contactar con los hombres en la vía pública para ofrecerles servicios sexuales (Villacampa 2017). Se han localizado 51 municipios con sanciones municipales por ofrecimiento de servicios y contacto en la vía pública ${ }^{26}$. El primero de ellos surge en el 2005 y los últimos localizados son del 2015. Se muestra la distribución en el grafico 1.

26 Este trabajo se ha realizado desde los estudios mencionados por la autora pero que no ha sido publicado y se ofrece en este trabajo un avance. 


\section{Gráfico 1. Aparición de las sanciones municipales por años}

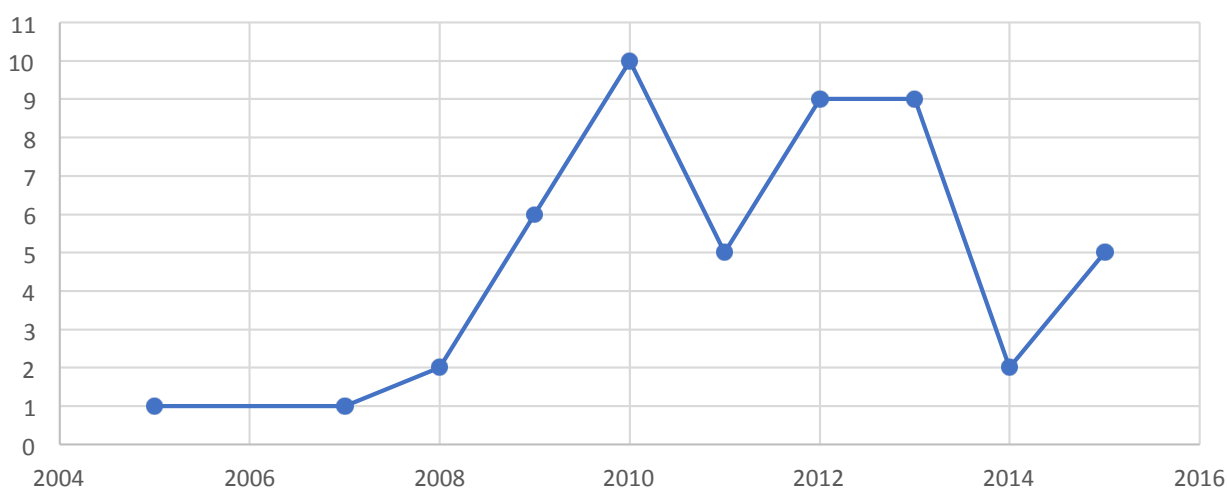

Por comunidades Autónomas son Valencia y Andalucía las que más Municipios poseen con sanciones municipales a las mujeres que ejercen la prostitución y a sus clientes. El 68\% (34) de estas sanciones se impusieron cuando estaba gobernando el Partido Popular, el 18\% (9) eran grupos independientes y el 14\% (7) fue el Partido Socialista.

Las mujeres que ejercen la prostitución en la vía pública suelen ser las más vulnerables y un sector de ellas está controlada y explotada por redes de proxenetas o tratantes, generalmente de procedencia subsaharianas y de Europa del este. El dinero que consiguen de los servicios sexuales es recaudado por estos tratantes en concepto de deuda por haberlas posibilitado la entrada y estancia en España. Las mujeres pueden estar amenazadas e incluso ser agredidas si no cumplen con el cometido que se esperan de ellas. Si son multadas los tratantes tomarán represalias sobre ellas. Por otra parte, tendrán una relación de desconfianza y recelo con la policía que será la encargada de ejecutar las sanciones, y aunque sea la policía local o municipal, ellas no los distinguirán entre estos dos cuerpos si están recién llegadas. Esta visión de la policía repercute negativamente en la posibilidad de que puedan denunciar a sus tratantes o proxenetas. La criminalización de la prostitución hace que prevalezca en mayor medida los controles y políticas migratorias que realmente la detección de víctimas de trata.

La estigmatización que la sociedad atribuye a las mujeres que ejercen la prostitución impide que pueda existir otra mirada diferente y pensar que muchas de estas mujeres pueden estar siendo sometidas a realizar esta actividad.

Por último, existe otra realidad que en muchas ocasiones pasa desapercibida para los profesionales y genera problemas en la identificación. Muchas de las víctimas de trata, especialmente en aquella con finalidad sexual, no fueron detectadas 
como víctimas cuando sus tratantes las explotaron. Posteriormente, estas mujeres se implican como controladoras o explotadoras de otras mujeres recién llegadas de sus países de origen, como una manera de pagar su deuda. En ese momento son detenidas e identificadas como miembros de la red de tratantes (Meneses, Urío \& Uroz, 2019) sin indagar en su historia previa. A pesar de que la trata con fines de explotación para actividades delictivas está contemplado tanto en el Protocolo marco como en el Código Penal suele pasar desapercibida (Villacampa \& Torres, 2017), criminalizando a víctimas de trata.

\section{CONCLUSIONES}

Los esfuerzos realizados por la administración española desde que se introdujo la trata de seres humanos en el Código Penal en el 2010 han producido escasa identificación de personas como víctimas de trata, a pesar de las noticias de liberación de muchas de ellas por las $\mathrm{FCS}^{27}$ del Estado en los medios de comunicación social. En el periodo del 2014 al 2017 fueron identificadas en España 2.209 víctimas de trata con fines de explotación sexual y 439 con finalidad de explotación laboral, siendo la segunda mucho menor que la primera a pesar de que los estudios internacionales la sitúan en cabeza. Estos datos podrían significar una mayor atención a la trata con fines de explotación sexual que a la laboral, que pasaría desapercibida. Es posible que esa desigual atención se relacione con el énfasis en los debates sobre la consideración de la prostitución, sirviendo como argumento para criminalizarla (Weitzer, 2014).

El número total de víctimas es desconocido y es necesario realizar estimaciones rigurosas sobre la población victimizada, que nos ofrezcan las dimensiones del sector identificado y el que queda sin hacerlo, así como los mayores obstáculos para acceder a estas personas. Entre ellos la formación y conocimiento de los profesionales que pueden entrar en contacto con las personas victimizadas siguen siendo un reto a abordar y que facilitaría el aumento en las identificaciones como se ha puesto de relieve en algunos trabajos. Además, el que la trata esté centrada principalmente en la explotación sexual es un factor que contribuye a invisibilizar otras formas de trata. Los estereotipos sobre la imagen y características que se otorgan a quien es una víctima de trata (Cunningham \& Cromer, 2016) inciden negativamente en la identificación cuando no hay concordancia, pasando desapercibidas. La identificación de las víctimas de trata debería realizarse por un equipo psicosocial de la administración pública y no recaer exclusivamente en las FCS por muchas colaboraciones que éstos puedan obtener de las ONGs, dado que

\footnotetext{
${ }^{27}$ Fuerzas y Cuerpos de Seguridad.
} 
la policía es vista como agentes de desconfianza a los que temer, sintiéndose más víctimas de la policía que de los tratantes por su estatuto de irregularidad en España. A estos aspectos se añaden que las propias víctimas que sufren la situación de trata no se reconocen como tales porque no conocen sus derechos, además de poseer una percepción de que han negociado mal su proyecto migratorio con una actitud de resignación. Los esfuerzos futuros deben centrarse en la identificación y protección de las personas explotadas por la trata, articulando los recursos que se adapten a las necesidades de estas personas. Determinar los factores que pueden contribuir a una mejor identificación debe ser un asunto para la agenda de los futuros años, especialmente en la trata con fines de explotación laboral.

\section{BIBLIOGRAFÍA}

ACCEM (2008). La trata de personas con fines de explotación laboral. Madrid: ACCEM.

Agustín, L. (2004). Trabajar en la industria del sexo y otros tópicos migratorios. Bilbao: Gakoa.

Allain, J. (2019). Conceptualizing the exploitation of human trafficking. En Clark, J. \& Poucki S., Human Trafficking and modern day slavery. Los Angeles: Sage.

Alomar, M. \& Plasencia, X. (2014). Historias de tráfico, trata y prostitución. Proceso migratorio de mujeres nigerianas a Mallorca. Mallorca: Casal Petit. Disponible en: https://casalpetit.files.wordpress.com/2014/03/historias-de-trefbfbdfico-trata-y-prostituciefbfbdn-web.pdf

Castaños, M.J. (2014). Hacia un estatuto de protección para las víctimas de trata y las actuales formas de explotación de personas. Tesis doctoral. Madrid: Universidad Pontificia Comillas.

Cunningham, K. \& Cromer, L. (2016). Attitudes About Human Trafficking: Individual Differences Related to Belief and Victim Blame. Journal of Interpersonal Violence, 31 (2), 228-244.

De León, F.J. (2010). Spanish legislation against trafficking in human beings: punitive excess and poor victim's assistance. Crime Law Soc Change, 54, 381-409.

De Miguel, A. (2014). La prostitución de mujeres, una escuela de desigualdad humana. ILEMATA, 6 (16), 7-30.

Eurostat (2014). Trafficking in Human Beings. Luxemburgo: Unión Europea.

GRETA (2018). Report concerning the implementation of the Council of Europe Convention on Action against Trafficking in Human Beings by Spain. Estrasburgo: Council of Europa.

Hakim, C. (2019). Capital erótico. El poder de fascinar a los demás. Barcelona: Debate 
Juliano, D. (2002). La prostitución el espejo oscuro. Barcelona: Icaria.

Juliano, D. (2004). Excluidas y marginales: Una aproximación antropológica. Barcelona: Cátedra.

Lima de Pérez, J. (2015). Contrasting the Conceptualisation of Victims of Trafficking for Sexual Exploitation: A Case Study of Brazilians in Spain and Portugal. Eur J Crim Policy Res., 21, 539-563.

Malguesini, G. (coord.) (2006). Impacto de una posible normalización profesional de la prostitución en la viabilidad y sostenibilidad futura del sistema de pensiones de protección social. Informe ESCODE 2006. Madrid: Ministerio de Trabajo y Asuntos Sociales, Secretaría de Estado de la Seguridad Social, en línea.

Meneses Falcón, C., Uroz Olivares, J., Rúa Vieites A., Gortázar Rotaeche, C. \& Castaño Reyero, M.J. (2015). Apoyando a las víctimas de trata Las necesidades de las mujeres víctimas de trata con fines de explotación sexual desde la perspectiva de las entidades especializadas y profesionales involucrados. Propuesta para la sensibilización contra la trata. Disponible en: http://www.violenciagenero.msssi.gob.es/violenciaEnCifras/estudios/investigaciones/2015/ pdf/Apoyando_Victimas_Trata.pdf.

Meneses-Falcón, C. (2017). Sueños rotos: la trata de mujeres y niñas con fines de explotación sexual. En Blanco, A. \& López-Ruiz, J.A., Informe España 2017 (pp. 3-46). Madrid: Universidad Pontificia Comillas, Cátedra J.M. Martín Patiño.

Meneses-Falcón, C., Urío, S., \& Uroz-Olivares, J. (2019). Financing of Trafficking in Human Beings in Spain. En Shentov, O., Rusev, A. \& Antonopoulos, G. (eds.), Finanancing of Organised Crime: Human Trafficking in Focus. Sofia: CSD.

Noyori-Corbett, Ch. \& Moxley, D. (2017). A transnational feminist policy analysis of the Trafficking Victims Protection Act. Int J Social Welfare, 26, 107-115.

O'Connell, J. (2010). New Slavery, Old Binaries: Human trafficking and the borders of "freedom", Global Networks, 10, 244-249.

Piscitelli, A. (2012). Revisiting notions of sex trafficking and victims. Vibrant, 9 (1), 275-310.

Pomares, E. (2011). El delito de trata de seres humanos con finalidad de explotación laboral. Revista Electrónica de Ciencia Penal y Criminología, 13-15, 1-31.

Sanchis, E. \& Serra, I. (2011). El mercado de la prostitución femenina. Una aproximación desde el caso valenciano. Política y Sociedad, 48 (1), 175-192.

Steinfatt, T.M. \& Baker, S. (2011). Measuring the Extent of Sex Trafficking in Cambodia-2008. Bangkok: UNIAP Regional Management Office.

Surtees, R. (2008). Traffickers and trafficking in Southern and Eastern Europe: Considering the other side of human trafficking. European Journal of Criminology, 5 (1), 39-68. 
Thieman, I. (2016). Villains and Victims, but No Workers: Why a prosecution-focussed approach to human trafficking fails trafficked persons. Anti-trafficking Review, 6, 126-129.

U.S. Departamento de Estado (2010). Trafficking in Persons Report. 10 $0^{\text {th }}$ Edition. Washington: Department of State. United States of America.

Ventrella, M. (2017). Identifying Victims of Human Trafficking at Hotspots by Focusing on People Smuggled to Europe. Social Inclusion, 5 (2), 69-80.

Villacampa, C. (2017). Municipal ordinances and street prostitution in Spain. Eur. J. Crim. Policy Res., 23, 41-57.

Villacampa, C. \& Torres, N. (2017). Human Trafficking for Criminal Exploitation: The Failure to Identify Victims. Eur. J. Crim. Policy Res., 23, 393-408.

Weitzer, R. (2014). New Directions in Research on Human Trafficking. ANNALS, AAPSS, 653, 6-24. 